Original Article

\title{
Relationship between walking efficiency and muscular strength of the lower limbs in children with cerebral palsy
}

\author{
Minoru Kimoto RPT, PhD $\left.{ }^{1,2}\right)^{*}$, Kyoji Okada, MD, PhD ${ }^{1)}$, Hitoshi Sakamoto, MD, $\mathrm{PhD}^{2)}$, \\ TAKANORI Kondou, RPT ${ }^{3)}$, UKi KaWANOBE, RPT ${ }^{2)}$ \\ 1) Department of Physical Therapy, Akita University Graduate School of Health Sciences: \\ 1-1-1 Hondo, Akita 010-8543, Japan \\ 2) Department of Medicine, Akita Prefectural Center on Development and Disability, Japan \\ 3) Department of Functional Training, Akita Prefectural Center for Rehabilitation and Psychiatric \\ Medicine, Japan
}

\begin{abstract}
Purpose] In children with cerebral palsy, despite increases in muscle strength after strengthening, improvements in walking efficiency are inconsistent in previous studies. The purpose of this study was to analyze the relationship between walking efficiency and muscle strength in children with cerebral palsy. [Participants and Methods] Twenty-six children with cerebral palsy participated in this study. Isometric muscle strength in the lower extremities and the Total Heart Beat Index were measured. Participants were divided into the high and low walking efficiency groups based on the median Total Heart Beat Index value ( 2.06 beats $/ \mathrm{m})$. [Results] For all participants, all isometric muscle strength values were significantly correlated with the Total Heart Beat Index. In the high walking efficiency group, there was no significant correlation. All isometric muscle strength values in the low walking efficiency group were significantly correlated with the Total Heart Beat Index, except for that of the hip extensors. [Conclusion] The influence of muscular strength on walking efficiency in children with cerebral palsy varied. Significant correlations were observed only for those in the low walking efficiency group. The walking efficiency level should be confirmed before planning muscle strength training to improve walking efficiency. Key words: Cerebral palsy, Muscle strength, Total Heart Beat Index
\end{abstract}

(This article was submitted Oct. 4, 2018, and was accepted Dec. 10, 2018)

\section{INTRODUCTION}

Cerebral palsy (CP) describes disorders of the development of movement and posture that cause activity limitation and are attributed to non-progressive disturbances of the fetal or infant brain ${ }^{1)}$. Children with $\mathrm{CP}$ have several clinical features, including spasticity, co-contraction, and weakness ${ }^{2}$. Children with $\mathrm{CP}$ who are able to walk expend a great deal of energy per unit of time ${ }^{3,4}$. Therefore, their walking efficiency (WE) is lower, or energy cost is higher than that of children with typical development. Low WE causes fatigue during walking and limits participation in community activities ${ }^{4}$. It is important to determine influential factors and establish a standard of training or treatment for WE.

Previously conducted studies have shown inconsistent effects of physical therapy for muscle strength and $\mathrm{WE}^{5-8)}$. $\mathrm{Kramer}$ et al. and Damiano et al. reported that muscle strength was correlated with WE in children with $\mathrm{CP}^{6,9)}$. Furthermore, an interventional study was conducted to increase muscle strength and $\mathrm{WE}^{5,6}$. However, Liao et al. and Kusumoto et al. researched whether sit-to-stand training has an effect on WE for children with $\mathrm{CP}$ and showed that WE improved without increasing the knee extension strength ${ }^{7,8)}$. The relationships between muscle strength and WE are not proportionate in all studies.

*Corresponding author. Minoru Kimoto (E-mail: minoru-kimoto@hs.akita-u.ac.jp)

(C2019 The Society of Physical Therapy Science. Published by IPEC Inc.

(c) (1) $\odot$ This is an open-access article distributed under the terms of the Creative Commons Attribution Non-Commercial No Derivatives cC. 
To explain the inconsistency, it was hypothesized that the relationship between muscle strength and functional activity performance is not straightforward. Walking requires a certain amount of muscle strength. Increases above the lower threshold may be achieved by increasing the walking ability. However, walking ability might not change to a level above the upper threshold of muscle strength ${ }^{9-11)}$. Therefore, muscle strength might not have any significant correlation above a certain level of WE.

The purpose of this study was to analyze the relationship between WE and muscle strength and to clarify the differences between children with CP with sufficient ambulation and those with non-efficient ambulation.

\section{PARTICIPANTS AND METHODS}

Twenty-six children (17 boys, 9 girls) with spastic diplegic CP who were treated at the inpatient and outpatient clinics of the Akita Prefectural Center on Development and Disability participated in the study. Participants were classified as having level I or level II ability based on the gross motor function classification system (GMFCS) ${ }^{12}$. All participants were able to follow verbal instructions. Participants who had undergone orthopedic surgery, botulinum toxin injection, and/or serial casting within 6 months were excluded from the study. Approval for this study was obtained from the medical ethics committee at the Akita University (receptive Number 567). Participants and parents received an explanation of the purpose and methods of this study, and written informed consent was obtained prior to initiation of the study.

Walking efficiency was determined using the total heart beat index (THBI) ${ }^{13)}$. Lower value of THBI indicate good walk efficiency or low energy cost. Participants walked at a self-selected speed on a rectangular walkway (10 $\mathrm{m}$ long, $7 \mathrm{~m} \mathrm{wide})$, and the distance walked in 10 minutes was measured as the walking distance. Heartbeats were monitored using a wearable heart rate monitor (RS800 CX; Polar Electro Oy, Kempele, Finland). Heartbeats during 10 minutes of walking were counted (walking heartbeats) and $\mathrm{THBI}^{13)}$ was calculated using the following formula:

THBI (beats per meter [beats / $\mathrm{m}]$ ) = walking heartbeats / walking distance ${ }^{13)}$.

A hand-held dynamometer ( $\mu$ Tas F-1; Anima Crop., Tokyo, Japan) was used to measure isometric muscle strength. Standard test positions were used, and the following muscle groups were evaluated bilaterally: hip flexors ${ }^{14,15)}$, extensors ${ }^{14)}$, and abductors $^{15,16)}$; knee flexors ${ }^{14,15)}$ and extensors ${ }^{15,16)}$; and ankle plantar flexors ${ }^{17)}$. The length of the lever arm was measured with a tape measure from bony landmarks (greater trochanter, lateral knee joint, lateral malleolus) to the center of the handheld dynamometer head. The torque-to-weight ratio $(\mathrm{nm} / \mathrm{kg})$ was calculated by the maximum force value $(\mathrm{N})$ for each joint movement, length of the lever arm, and weight. The average value of the bilateral side was calculated.

The normality of each parameter was assessed using the Shapiro-Wilk test. The median value of THBI was calculated. Based on each THBI, the participants were divided into the following two subgroups: the high WE group with a lower THBI than the median value and the low WE group with a higher THBI than the median value. To detect differences in characteristics of the two groups, we conducted a two-sample t-test, Mann-Whitney U test, and $\chi^{2}$ test for each parameter. Pearson's product-moment correlation coefficient was used to analyze the relationship between normally distributed parameters obtained for THBI and muscle strength at each joint. Spearman's rank-correlation coefficients were used for other parameters. The significance level was $\mathrm{p}<0.05$.

\section{RESULTS}

Participant characteristics are presented in Table 1. The median of THBI was 2.06 beats $/ \mathrm{m}$. In the high WE group, few patients had GMFCS level II, although the numbers of patients with level I in the low WE group were almost similar to those with level II.

Correlations between the strength of each isometric muscle and THBI are shown in Table 2. THBI showed significant correlations with strength in all isometric muscles for all participants. In the low WE group, THBI showed significant correlations with the strength of all isometric muscles except for the hip extensors. In the high WE group, however, THBI was not related to the strength of any isometric muscle strength.

\section{DISCUSSION}

Several previous studies have researched relationships between WE and muscle strength ${ }^{6,18)}$. Damiano and Abel analyzed the mean of the strength of eight muscles in the lower extremities ${ }^{6}$. However, Goh et al. focused on only the strength of the knee muscles ${ }^{18)}$. The current study showed that THBI correlated with the strength of all isometric muscles. Each muscle has a role during the walking period. In particular, exerted joint moments during walking are similar to the maximum muscle strength of children with $\mathrm{CP}^{19}$ ). For children with $\mathrm{CP}$ who need to exert maximum muscle strength during walking, any decreases in muscle strength would cause inefficient gait. More recent intervention studies have shown an extraordinary phenomenon that WE improves without increasing muscle strength of the knee extensors after sit-to-stand training ${ }^{7,8)}$. Because the training included standing and sitting exercises, the strength of not only the knee extensors but also the hip extensors would be increased after training. The results of this study indicate that intervention studies have confirmed the influence of training several joints used for muscle strength and WE. 
Table 1. Characteristics of participants and subgroups

\begin{tabular}{lccc}
\hline & All participants & High WE group & Low WE group \\
& $\mathrm{n}=26$ & $\mathrm{n}=13$ & $\mathrm{n}=13$ \\
\hline Age $(\mathrm{y}: \mathrm{mo})$ & $12: 5(2: 8)$ & $13: 5(2: 4)$ & $11: 6(3: 0)$ \\
Gender $(\mathrm{M} / \mathrm{F})$ & $17 / 9$ & $8 / 5$ & $9 / 4$ \\
Height $(\mathrm{cm})$ & $142.2(16.1)$ & $148.2(10.9)$ & $136.1(18.5)$ \\
Weight $(\mathrm{kg})$ & $39.8(14.7)$ & $43.8(11.6)$ & $35.8(16.8)$ \\
GMFCS level I/II & $18 / 8$ & $12 / 1$ & $6 / 7^{\mathrm{c}}$ \\
GMFM $(\%)$ & $94.0(5.8)$ & $98.1(2.3)$ & $90.1(5.8)^{\mathrm{b}}$ \\
THBI $($ beats/m) & $2.12(0.45)$ & $1.75(0.25)$ & $2.49(0.25)^{\mathrm{a}}$ \\
\hline
\end{tabular}

Value are mean (SD). WE: walking efficiency; GMFCS: gross motor function classification system; GMFM: gross motor function measure; THBI: Total Heart Beat Index. ${ }^{\mathrm{a}} \mathrm{p}<0.05$, two-sample t-test.

${ }^{\mathrm{b}} \mathrm{p}<0.05$, Mann-Whitney U test. ${ }^{\mathrm{c}} \mathrm{p}<0.05, \chi^{2}$ test.

Table 2. Correlation coefficients of isometric muscle strength and Total Heart Beat Index for participants and subgroups

\begin{tabular}{lccc}
\hline & All participants & High WE group & Low WE group \\
\hline Hip flexors & $-0.670^{\mathrm{b}}, \mathrm{n}=26$ & $-0.291, \mathrm{n}=13$ & $-0.726^{\mathrm{a}}, \mathrm{n}=13$ \\
Hip extensors & $-0.459^{\mathrm{a}}, \mathrm{n}=25$ & $-0.306, \mathrm{n}=12$ & $-0.451, \mathrm{n}=13$ \\
Hip abductors & $-0.715^{\mathrm{a}}, \mathrm{n}=26$ & $-0.368, \mathrm{n}=13$ & $-0.656^{\mathrm{a}}, \mathrm{n}=13$ \\
Knee flexors & $-0.737^{\mathrm{a}}, \mathrm{n}=26$ & $-0.512, \mathrm{n}=13$ & $-0.632^{\mathrm{b}}, \mathrm{n}=13$ \\
Knee extensors & $-0.607^{\mathrm{a}}, \mathrm{n}=26$ & $-0.157, \mathrm{n}=13$ & $-0.742^{\mathrm{b}}, \mathrm{n}=13$ \\
Ankle planter flexors & $-0.562^{\mathrm{a}}, \mathrm{n}=25$ & $-0.307, \mathrm{n}=12$ & $-0.577^{\mathrm{a}}, \mathrm{n}=13$ \\
\hline
\end{tabular}

${ }^{\mathrm{a}} \mathrm{p}<0.05$, Pearson's product moment correlation coefficient.

${ }^{\mathrm{b}} \mathrm{p}<0.05$, Spearman's rank correlation coefficient.

No significant correlation was observed between THBI and isometric strength in the high WE group. The median THBI was 2.06 beats $/ \mathrm{m}$ in the current study. For children with typical development, the range of THBI was $1.11-2.13 \mathrm{beats} / \mathrm{m}^{20}$. By separating participants according to the median THBI, we created two subgroups consisting of those with normal WE and those with low WE. The results of this study showed that children with CP with normal WE would not be influenced by any isometric muscle strength, indicating that increasing muscle strength could not affect improvement in WE for these children. In the current high WE group, almost all participants had GMFCS level I. With milder CP, spasticity, contracture, and/or deformity probably influence WE.

However, the strength of each isometric muscle showed a significant correlation with THBI in the low WE group, except for the hip extensors. In the low WE group, children were considered to be dependent on muscular strength during walking. These results led us to conclude that THBI changes with isometric muscle strength in children with CP and low WE. The exception of the hip extensors in the low WE group might be a concern; therefore, they should be tested. The test position used in this study involved the hips flexed 90 degrees in the supine position. When measuring isometric muscle strength, the value changed depending on the measuring angle. In the hip extensors, the muscle strength during hip flexion of 90 degrees was twice the value of that of the extended hip in a previous study ${ }^{14}$. The test position of the hip extensors could explain their exception from the relationship between WE and muscle strength in the low WE group.

A limitation of this study was that isometric muscle strength indicated only the strength of partial range of motion. It is possible that measurements during the extension position of the hip might be strongly influenced by spasticity and contracture of the hip flexors. Goh et al. reported that muscle strength of the knee extensors was influenced by the spasticity of the hamstrings ${ }^{18)}$. Muscle strength should be measured in the entire range of motion.

The current study provided evidence that WE is influenced by the strength of several muscles of the lower extremity. In addition, it was clarified that the influence of muscular strength on WE varies according to the level of WE in children with CP. Whether a level of WE is low or normal should be confirmed before planning muscle strength training and treatments.

\section{Conflict of interest}

None. 


\section{REFERENCES}

1) Bax M, Goldstein M, Rosenbaum P, et al. Executive Committee for the Definition of Cerebral Palsy: Proposed definition and classification of cerebral palsy, April 2005. Dev Med Child Neurol, 2005, 47: 571-576. [Medline] [CrossRef]

2) Kerr Graham H, Selber P: Musculoskeletal aspects of cerebral palsy. J Bone Joint Surg Br, 2003, 85: 157-166. [Medline] [CrossRef]

3) Rose J, Morgan DW, Gamble JG: Energetics of walking. In: Human walking, 3rd ed. Philadelphia: Lippincott Williams \& Wilkins, 2006, pp77-102.

4) Kerr C, McDowell BC, Parkes J, et al.: Age-related changes in energy efficiency of gait, activity, and participation in children with cerebral palsy. Dev Med Child Neurol, 2011, 53: 61-67. [Medline] [CrossRef]

5) MacPhail HE, Kramer JF: Effect of isokinetic strength-training on functional ability and walking efficiency in adolescents with cerebral palsy. Dev Med Child Neurol, 1995, 37: 763-775. [Medline] [CrossRef]

6) Damiano DL, Abel MF: Functional outcomes of strength training in spastic cerebral palsy. Arch Phys Med Rehabil, 1998, 79: 119-125. [Medline] [CrossRef]

7) Liao HF, Liu YC, Liu WY, et al.: Effectiveness of loaded sit-to-stand resistance exercise for children with mild spastic diplegia: a randomized clinical trial. Arch Phys Med Rehabil, 2007, 88: 25-31. [Medline] [CrossRef]

8) Kusumoto Y, Nitta O, Takaki K: Impact of loaded sit-to-stand exercises at different speeds on the physiological cost of walking in children with spastic diplegia: a single-blind randomized clinical trial. Res Dev Disabil, 2016, 57: 85-91. [Medline] [CrossRef]

9) Bohannon RW: Muscle strength and muscle training after stroke. J Rehabil Med, 2007, 39: 14-20. [Medline] [CrossRef]

10) Shortland A: Muscle deficits in cerebral palsy and early loss of mobility: can we learn something from our elders? Dev Med Child Neurol, 2009, 51: 59-63. [Medline] [CrossRef]

11) Scholtes VA, Becher JG, Janssen-Potten YJ, et al.: Effectiveness of functional progressive resistance exercise training on walking ability in children with cerebral palsy: a randomized controlled trial. Res Dev Disabil, 2012, 33: 181-188. [Medline] [CrossRef]

12) Palisano RJ, Hanna SE, Rosenbaum PL, et al.: Validation of a model of gross motor function for children with cerebral palsy. Phys Ther, 2000, 80: $974-985$ [Medline]

13) Hood VL, Granat MH, Maxwell DJ, et al.: A new method of using heart rate to represent energy expenditure: the Total Heart Beat Index. Arch Phys Med Rehabil, 2002, 83: 1266-1273. [Medline] [CrossRef]

14) Crompton J, Galea MP, Phillips B: Hand-held dynamometry for muscle strength measurement in children with cerebral palsy. Dev Med Child Neurol, 2007, 49: 106-111. [Medline] [CrossRef]

15) Katoh M, Yamasaki H: Comparison of reliability of isometric leg muscle strength measurements made using a hand-held dynamometer with and without a restraining belt. J Phys Ther Sci, 2009, 21: 37-42. [CrossRef]

16) Berry ET, Giuliani CA, Damiano DL: Intrasession and intersession reliability of handheld dynamometry in children with cerebral palsy. Pediatr Phys Ther, 2004, 16: 191-198. [Medline] [CrossRef]

17) Taylor NF, Dodd KJ, Graham HK: Test-retest reliability of hand-held dynamometric strength testing in young people with cerebral palsy. Arch Phys Med Rehabil, 2004, 85: 77-80. [Medline] [CrossRef]

18) Goh HT, Thompson M, Huang WB, et al.: Relationships among measures of knee musculoskeletal impairments, gross motor function, and walking efficiency in children with cerebral palsy. Pediatr Phys Ther, 2006, 18: 253-261. [Medline] [CrossRef]

19) Dallmeijer AJ, Baker R, Dodd KJ, et al.: Association between isometric muscle strength and gait joint kinetics in adolescents and young adults with cerebral palsy. Gait Posture, 2011, 33: 326-332. [Medline] [CrossRef]

20) Plasschaert F, Jones K, Forward M: The effect of simulating weight gain on the energy cost of walking in unimpaired children and children with cerebral palsy. Arch Phys Med Rehabil, 2008, 89: 2302-2308. [Medline] [CrossRef] 